\title{
Arterial Variations Within the Lateral Cervical Region: A Multidetector CT Angiography Study
}

\author{
Variaciones Arteriales en la Región Cervical Lateral: \\ Estudio Angiográfico por Tomografía Computarizada Multidetector
}

\author{
Erdogan Bulbul ${ }^{1}$; Bahar Yanik ${ }^{1}$; Emrah Akay ${ }^{1}$; Vildan Koksal ${ }^{2} \&$ Gulen Demirpolat $^{1}$
}

\begin{abstract}
BULBUL, E.; YANIK, B.; AKAY, E.; KOKSAL, V. \& DEMIRPOLAT, G. Arterial variations within the lateral cervical region: A multidetector CT angiography study. Int.J. Morphol., 37(3):991-996, 2019.

SUMMARY: It is important to know the arterial anatomy within the lateral cervical region before the flap-planning. We evaluated the arterial anatomy in this area using multidetector computed tomography (CT) angiography and our aim was to establish the arterial variations. Both sides of individuals in a total number of 155 carotid CT angiographies are reviewed by using 64-detector CT, retrospectively. The variations of suprascapular artery, superficial cervical artery, dorsal scapular artery that are inclusive of the lateral cervical region were assessed. Three arteries originated individually in $67(23.8 \%)$ sides. They arose by trunk formation in 214 (76.2\%) sides. The most common type of trunk formation was cervicodorsal trunk (107; $38 \%)$. The others were cervicoscapular trunk, cervicodorsoscapular trunk, dorsoscapular trunk and detected in $66(23.4 \%), 40(14.3 \%), 1(0.3 \%)$ sides, respectively. The origins of arteries within the lateral cervical region may show variations and they may originate from subclavian artery or its branches individually or by trunk formations. It may be beneficial to know these variations before the reconstructive surgical procedures in head and neck. CT angiography is a non-invasive method that enables to evaluate the arterial anatomy and variations in this area.
\end{abstract}

KEY WORDS: Angiography; Artery; CT; Free tissue flaps; Lateral cervical region; Variations.

\section{INTRODUCTION}

The lateral cervical region lies between the posterior margin of sternocleidomastoid muscle anteriorly, anterior margin of trapezius muscle posteriorly and clavicula inferiorly (Moore et al., 2014). This area is widely used for harvesting flaps like musculocutaneous, vascularized supraclavicular lymph node transfer and dorsal scapular island flaps in plastic and reconstructive surgery (Angrigiani et al., 2003; Haas et al., 2004; Kim et al., 2016). Therefore it is important to know the proper arterial anatomy of this area for flap-planning.

The arterial anatomy and variations within the lateral cervical region are well documented in postmortem studies (Chaijaroonkhanarak et al., 2014; Weiglein et al., 2015). Three arteries [suprascapular artery (SSA), superficial cervical artery (SpCA), dorsal scapular artery (DScA)] may be used for flap harvesting lies within this region. These arteries may originate from subclavian artery (SCA), thyrocervical trunk, costovertebral trunk, thyrotoracal trunk or internal mammalian artery (IMA) individually or by forming trunks and show various types of origin. Four trunks formed by combination of abovementioned three arteries described in a previous study (Weiglein et al.). The cervicodorsal trunk (CDT) which is also called as transverse cervical artery, the cervicoscapular trunk (CST), the dorsoscapular trunk (DST) and the cervicodorsoscapular trunk (CDST) were reported (Fig. 1).

Computed tomographic (CT) angiography is a noninvasive and widely available method in detecting arterial pathologies and variations (Bozlar et al., 2003; Karaman et al., 2012; Calisir et al., 2015; De Beule et al., 2016). CT angiography can be used for preoperative planning before the flap harvesting from the lateral cervical triangle (Adams et al., 2012). However we did not find a CT angiographic study evaluating the variations at the origin of arteries and

\footnotetext{
${ }^{1}$ Balikesir University, School of Medicine, Department of Radiology, Balikesir, Turkey.

${ }^{2}$ Saglik Bilimleri University, Erzurum Bolge Egitim ve Arastirma Hastanesi, Radiology Department, Erzurum, Turkey.
} 


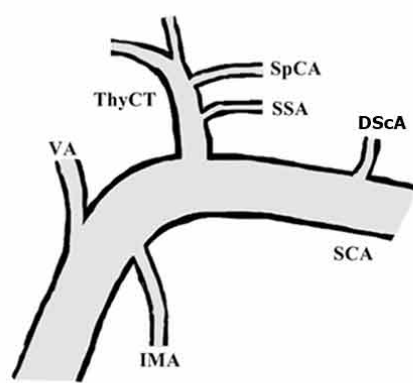

INDIVIDUAL TYPE

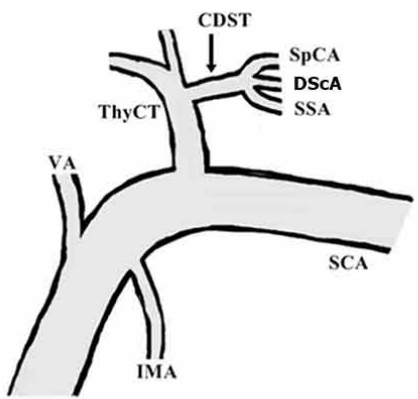

CDST TYPE

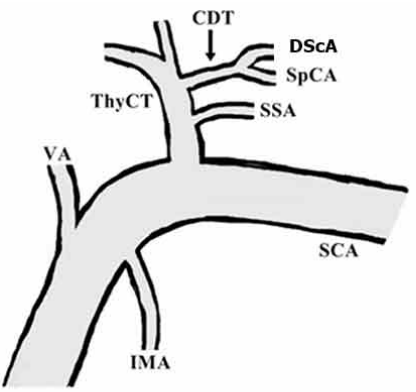

CDT TYPE

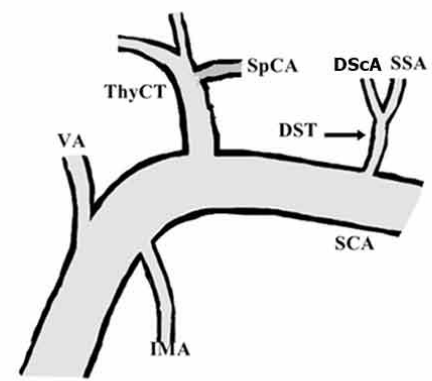

DST TYPE

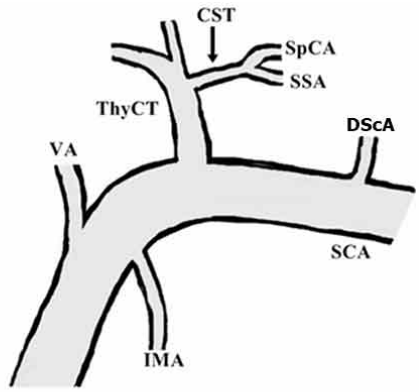

CST TYPE

Fig.1. llustration of individual type and trunk formations within the lateral cervical region. (CDT: cervicodorsal trunk; CDST: cervicodorsoscapular trunk; CST: cervicoscapular trunk; DScA: dorsal scapular artery; DST: dorsoscapular trunk; IMA: internal mammarian artery; SCA: subclavian artery; SpCA: superficial cervical artery; SSA: suprascapular artery; ThyCT: tyhro-cervical trunk; VA: vertebral artery)

trunks within the lateral cervical region. In this study, we retrospectively reviewed this area in the carotid artery $\mathrm{CT}$ angiographies and analyzed the branching types of arteries and trunks.

\section{MATERIAL AND METHOD}

Patient selection. Between September 2014 and December 2016, 155 patients were performed CT angiography for suspected carotid and vertebral artery diseases at our radiology clinic. We retrospectively reviewed SCAs in these $\mathrm{CT}$ angiograms to evaluate the origins of arteries and trunks within the lateral cervical region. Patients with unilateral or bilateral inadequate exams because of technical failure, previous cervical surgery history and aberrant right SCA were excluded. The ethics committee of our institution approved the study (approval number: 2017/17).

Imaging technique and analysis. All patients underwent routine diagnostic $\mathrm{CT}$ angiography imaging of the carotid and vertebral arterial system performed at 64 slice multidetector CT scanner (Toshiba Aquillon 64, Otawara, Japan). The collimation used was $40 \mathrm{~mm}$ with a slice thickness of $0.5 \mathrm{~mm}, 0.3 \mathrm{~mm}$ spacing and a pitch of 1.0 . The patient was placed on the scanner table; head first, in a supine position. Antero-posterior and lateral scout films were obtained. The scan delay is set using automated bolus tracking software (SureStart, Toshiba Medical Systems) to capture $150 \mathrm{HU}$ of the arcus aorta. The scan range was from the arcus aorta to head including the circle of Willis. Scanning was done by administering $90-100 \mathrm{ml}$ of non-ionic contrast at an injection rate of $4 \mathrm{ml} / \mathrm{s}$. A single acquisition protocol with an automatic triggering system was used. After image acquisition, the raw data were processed and transferred in the Digital Imaging and Communications in Medicine standard (DICOM) format to the TeraRecon (AquariusNET Workstation 4.4.7) workstation capable of advanced image processing and manipulation. The data were systematically analyzed using maximum intensity projection (MIP) and multiplanar reformat (MPR) slices in coronal, sagittal, and oblique planes. Three-dimensional volume rendering (3DVR) in different planes was used to optimize spatial 
orientation. Curved planar reformat (CPR) planes/lumen curved planar reformat planes were then used to demonstrate arterial origins. Axial slices were used to confirm and adjudicate the origin of arteries. We classified the types of the arterial and trunk origins similarly described by Weiglein et al. Classification of anatomical variations was performed by the two radiologists with 10 years of experience in angiography including CT imaging.

This retrospective study was approved by the local ethic committee.

\section{RESULTS}

The patients were 49 females and 97 males; aged between 29 and 88 years old (mean age 65.4 years old). Bilateral SCAs in 135 patients, unilateral SCA in 11 patients and totally 281 sides were included to our study. 95 sides in 49 females and 186 sides in 96 males were evaluated. Both sides in 9 and unilateral side 11 patients were excluded.

Three arteries originated either by trunk formation or individually and five main branching types detected (Table I). In the first type, each of three arteries (SSA, SpCA or DScA) arose separately without forming a trunk (Fig. 2). This type was observed in $67(23.8 \%)$ sides. A trunk formation was observed in the remaining $214(76.2 \%)$ sides. Four trunk formations observed. The most common type of trunk formation was CDT $(107 ; 38 \%)$. CDT originated from the thyrocervical trunk in $52(18.5 \%)$ sides and directly from SCA in 55 (\%19.5) sides (Fig. 3). The second type of trunk was CST. It was detected in $66(23.4 \%)$ sides. The thyrocervical trunk was the origin of CST in $60(21.3 \%)$ sides (Fig. 4). CST arose from thyrotoracal trunkus in 3 ( $\% 1.1)$, SCA directly in $2(0.7 \%)$, IMA in $1(0.3 \%)$ sides, respectively. The third type of trunk formation was CDST

Table I. Branching types of arteries and trunks within the lateral cervical region detected in this study.

\begin{tabular}{lcc}
\hline Branching type & $\begin{array}{c}\text { Number of } \\
\text { sides }\end{array}$ & $\begin{array}{c}\text { Percentage } \\
(\%)\end{array}$ \\
\hline Individual origin of SSA, & 67 & 23.8 \\
SpCA and DScA & 214 & 76.2 \\
Trunk formation & 107 & 38 \\
CDT & 66 & 23.4 \\
CST & 40 & 14.3 \\
CDST & 1 & 0.3 \\
DST & 281 & 100
\end{tabular}

CDT: cervicodorsal trunk; CDST: cervicodorsoscapular trunk CST: cervicoscapular trunk; DScA: dorsal scapular artery; DST: dorsoscapular trunk; SpCA: superficial cervical artery; SSA: suprascapular artery.

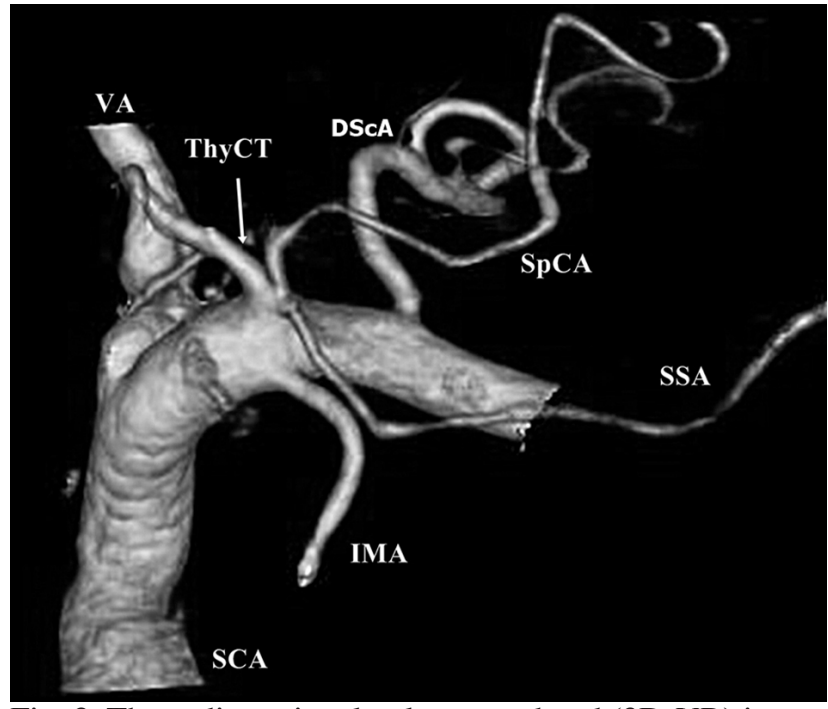

Fig. 2. Three-dimentional volume rendered (3D-VR) image demonstrates SpCA and DScA arising from ThyCT and SSA originating from SCA individually without trunk formation.

which was detected in $40(14.3 \%)$ sides (Fig. 5). CDST originated from thyrocervical trunk in $35(12.5 \%)$ sides, directly from SCA in $3(1.1 \%)$ sides, IMA in $1(0.3 \%)$ side and thyrothoracal trunk in $1(0.3 \%)$ side. DST was the least trunk formation detected in our study. One DST $(1 ; 0.3 \%)$ arose directly from SCA.

The CDT (R 55, $39.5 \%$; L 53, $36.8 \%$ ) was the most common branching type in both right and left sides. The others were individual arising of arteries $(35 ; 25.5 \%)$, CST $(34,25 \%)$, CDST $(15,11 \%)$ and CST $(33,23 \%)$, individual arising of arteries $(32,22.2 \%), \operatorname{CDST}(25,17.8 \%)$ in right and left sides, respectively. DST formation was detected once $(0.7 \%)$ in the left side, but was not seen in the right.

The frequency of branching types in both gender were similar, however some differences in the incidences detected. The CDT was the most common type in both genders. CDT $(64 ; 33 \%)$, CST $(50 ; 26.9 \%)$, individual arising of arteries $(39,21 \%)$, CDST $(32 ; 17.2 \%)$ and CDT $(43 ; 45 \%)$, individual arising of arteries $(28 ; 29.5 \%)$, CST $(16 ; 16.9 \%)$, CDST $(8 ; 8.4 \%)$ detected in males and female respectively. DST was found in 1 a male; however did not detected in females.

The SSA mostly originated separately from the thyrocervical trunk $(167 ; 56.6 \%)$. The other origins were CST (66; $23.5 \%)$, CDST (40; $14.2 \%)$, IMA (7; $2.5 \%)$, SCA $(4 ; 1.4 \%)$, DST $(1,0.3 \%)$, respectively. SpCA origin was originated from CDT $(107 ; 38 \%)$, CST $(66 ; 23.5 \%)$, thyrocervical trunk $(65 ; 23.1 \%)$, $\operatorname{DCST}(40 ; 14.2 \%)$ and SCA $(3 ; 1 \%)$. 

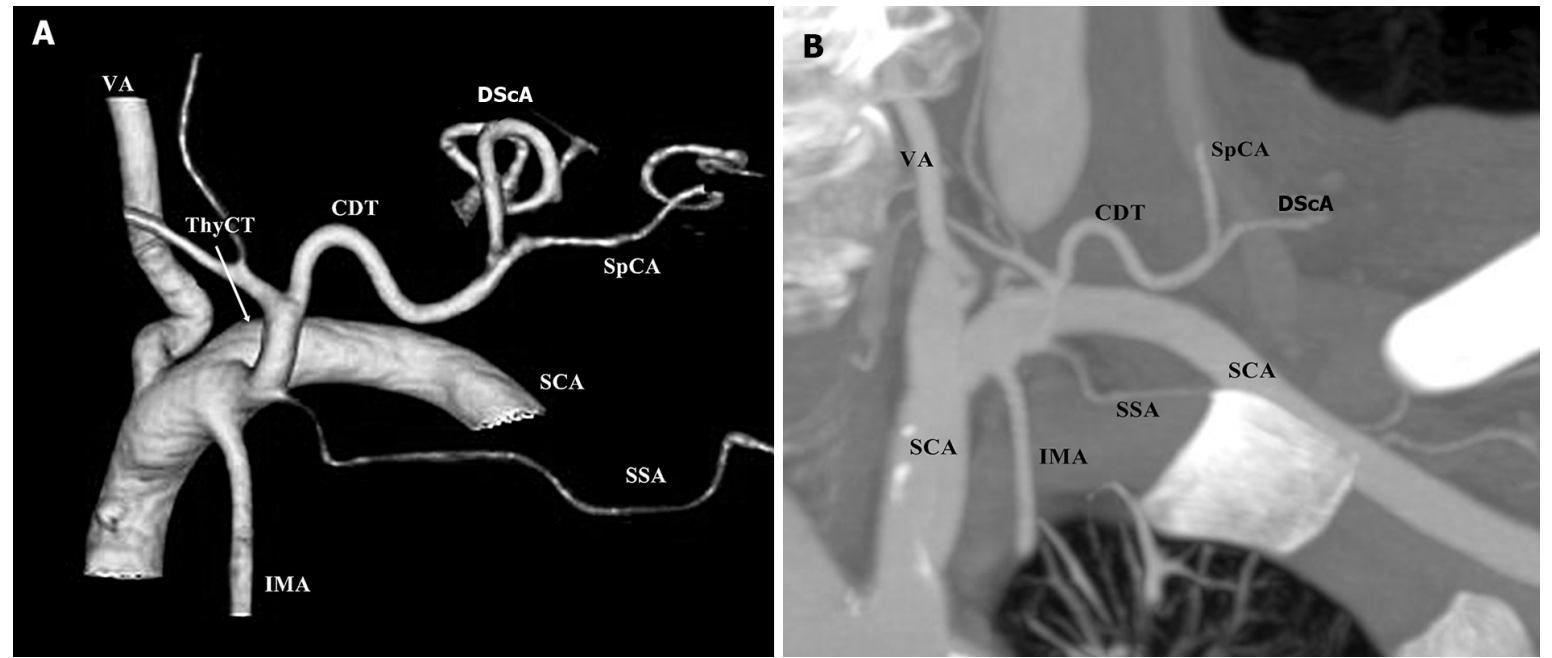

Fig. 3. CDT formation type. 3D-VR image shows the SpCA and DScA originate from ThyCT and form CDT (A). SSA also originate from ThyCT however does not join to trunk formation. Coronal maximum intensity projection (MIP) image shows CDT formation in same patient (B).
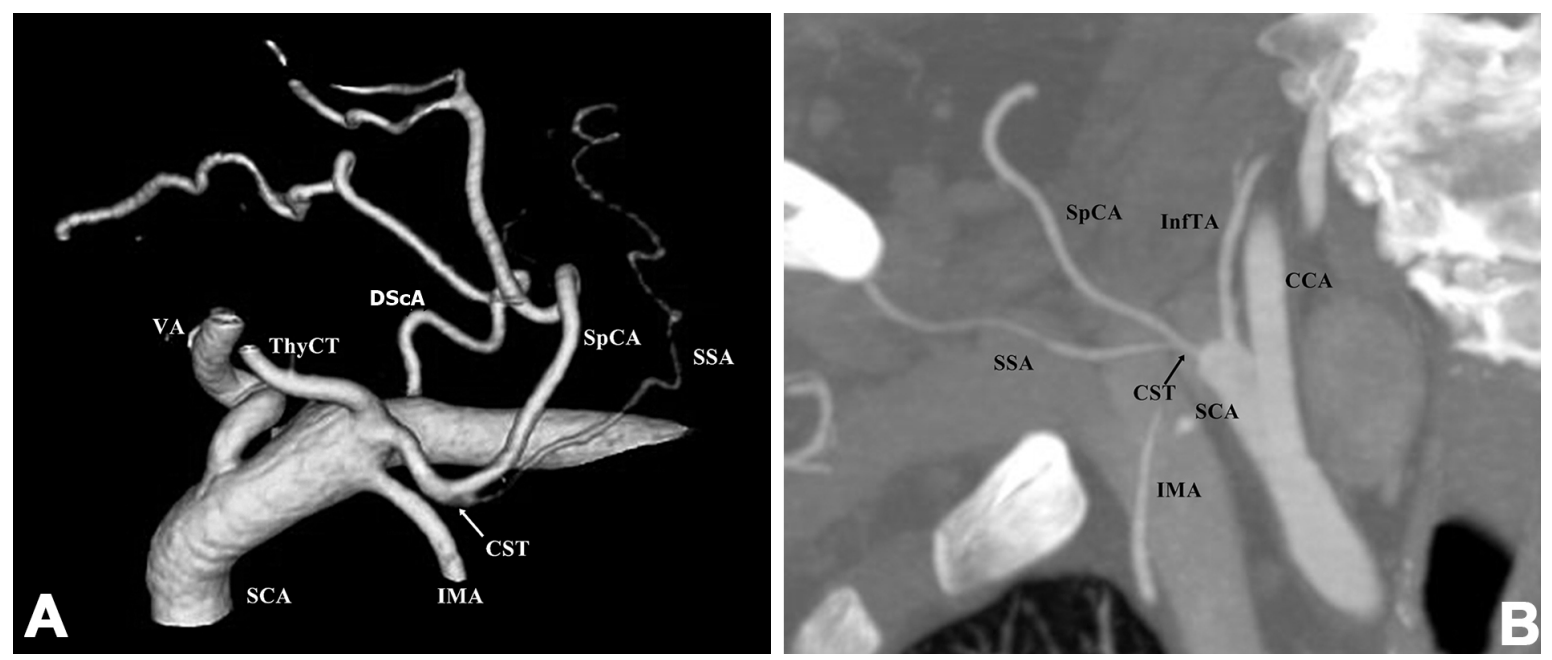

Fig. 4. CST formation type. 3D-VR image demonstrates the CST arising from the ThyCT (A). MIP image shows CST arising from the SCA directly in another patient (B).

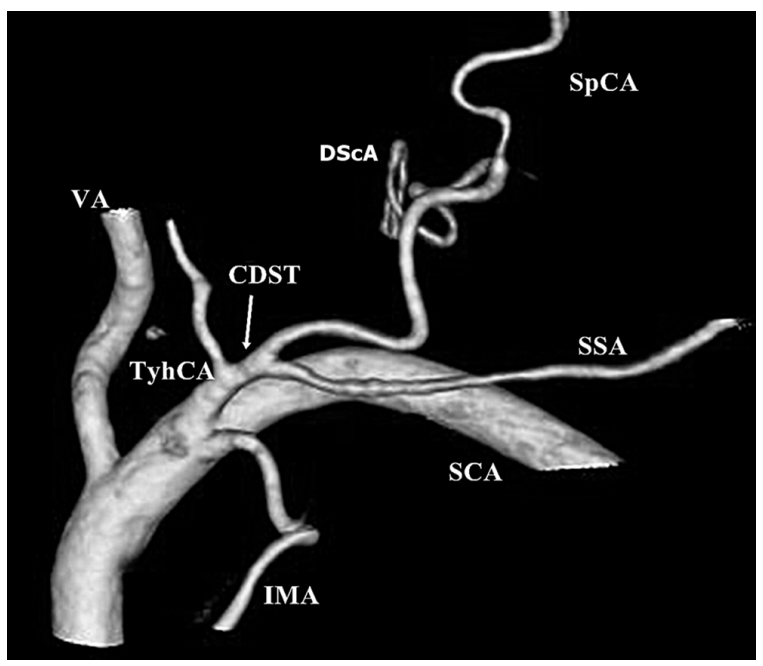

994
DScA originated from SCA separately in 128 $(45.6 \%)$ sides. The other origins were CDT $(107 ; 38$ $\%)$, CDTS $(40 ; 14.2 \%)$, costocervical trunk $(5 ; 1.8 \%)$ and DST $(1 ; 0.3 \%)$.

\section{DISCUSSION}

In this study we evaluated the variations of arteries and trunks within the lateral cervical region with CT angiography. The arteries were usually

Fig. 5. CDST formation type. In 3D-VR image SSA, SpCA and $\mathrm{DScA}$ originates all together from ThyCT with common trunk formation. 
originated by trunk formation. They sometimes aroused individually from SCA or its branches.

DScA may originate directly from SCA or may form CDT with SpCA. CDT is also called as transverse cervical artery (Weiglein et al.). CDT may arise from thyrocervical trunk or SCA (Murata et al., 2012). This trunk lies above the inferior belly of omohyoid muscle to anterior margin of trapezius muscle and diverges into two branches. SpCA ascends beneath the anterior edge of trapezius muscle and supplies the surrounding lymph nodes and muscles. DScA passes below the levator scapula muscle and reaches the superior corner of scapula, supplies the levator scapula, trapezius and rhomboid muscles (Moore et al.).

CDT formation was investigated with cadaveric studies and a broad incidence range between $22.4 \%$ and $77.5 \%$ found (Lischka et al., 1982; Weiglein et al.). CDT was detected arising from SCA, thyrocervical trunk and IMA in previous studies. CDT formation range was compatible with literature and calculated $38 \%$ in our study. We observed CDT to arised from SCA or thyrocervical trunk. We did not see a CDT arising from IMA. CDST, CST and DST were the other trunk formation types described by Weiglein et al. These trunks were found in $24 \%, 22 \%$ and $4 \%$ specimens, respectively. We detected them with the same descending order.

The origin of DScA was reported usually CDT or SCA, however the most common site may change among the ethnicities. Chaijaroonkhanarak et al. and Komada et al. found the DScA mostly arose from CDT in Thais and Japanese, nevertheless Reiner \& Kasser (1996) reported the DScA mostly from SCA (Sato et al., 2012; Chaijaroonkhanarak et al.). Additionally Weiglein et al. reported other possible sites like CST, CDST, IMA and costocervical trunk for DScA origin. In our study SCA and CDT were common sides for DScA origin and we also detected the other possible origins except IMA.

There is limited number of radiologic studies interested in the origin of arteries within the lateral cervical region. Patel et al. (2014) used color Doppler ultrasonography (CDUS) before the flap harvesting surgery. They evaluated the course of arteries but they did not take care of arterial origins. Gao et al. (2016) evaluated thoracic branch of SSA with CDUS before flap operation, however they did not interested in other arteries. Ikka et al. (2016) evaluated the origin of DScA in fresh cadavers and digital subtraction angiographies. They did not report the origins of other arteries within the lateral cervical region. Adams et al. reported the usefulness of CT angiography before flap harvesting. They only interested in supraclavicular artery and did not deal with the other arteries. As our best knowledge present study is the first one that investigated the branching types of lateral cervical region arteries with $\mathrm{CT}$ angiography.
Lateral cervical region arteries are important for flap harvesting in plastic and reconstruction surgery. Flaps including these arteries can be used in different kinds of procedures such as vascularized lymph node transfer, and head and neck reconstructions (Adams et al.; Atallah et al., 2015). Preoperative radiologic evaluation of pedicles may improve the safety and success of the operation, help choosing the optimal flap design and also prevent like ischemic complications (De Beule et al.). CT angiography is a noninvasive method that can be used for preoperative evaluation of vascular variations before the surgery (Tan et al., 2011). CT angiography has a high spatial resolution and can determinate the origins, branches and distribution of arteries although they are very thin (Smit et al., 2009; Ono et al., 2011). It has disadvantages like radiation exposure and contrast material related complications. Radiologists can assess arterial variations, the diameter and trajectory of the arteries with CT angiography (De Beule et al.). The use of digital subtraction angiography is limited for preoperative vascular evaluation because of its invasive nature and potential complications although it is considered to be the gold standard for vascular imaging (Shareghi et al., 2010). CDUS is a non-invasive method that can be used for evaluation lateral cervical region arteries (Abrahams et al., 2008). However it is an operator dependent method and has lower resolution (Gao et al.). CDUS may be insufficient to detect the variations and course of the arteries (Tan et al.). Magnetic resonance angiography (MRA) is another method for arterial evaluation. It has can provide three-dimentional imaging like CT angiography and no radiation exposure. Otherwise MR angiography cannot detect arteries less than $1.0 \mathrm{~mm}$ diameter and costs higher and it is not widely available (Rozen et al., 2008).

Our study has some limitations. Our study was retrospective and findings were obtained only with CT angiography. We could not correlate our findings with other imaging modalities. We could not collect the data from a great number of subjects, so this study may be confirmed with larger amount of data. Another limitation was occurred because of technical limitations. In some subjects we could not evaluate the arteries because of the artifacts caused by the neighboring contrast material filled veins especially at the injection sides.

\section{CONCLUSIONS}

The origins of SpCA, DScA and SSA may show variations and they may originate from SCA or its branches individually or by forming trunks. In this study we evaluated the origins of lateral cervical region arteries with CT angiography. They mostly originated by forming trunks and CDT was the most detected type. CT angiography is a helpful 
and a non-invasive method in determining the variations of lateral cervical region arteries and may be useful before the vascularized flap operations.

BULBUL, E.; YANIK, B.; AKAY, E.; KOKSAL, V. \& DEMIRPOLAT, G. Variaciones arteriales en la región cervical lateral: estudio angiográfico por tomografía computarizada multidetector. Int. J. Morphol., 37(3):991996, 2019 .

RESUMEN: Es importante conocer la anatomía arterial de la región cervical lateral antes de la planificación de un colgajo. Evaluamos la anatomía arterial en esta área mediante angiografía con tomografía computarizada (TC) multidetector con el objetivo de establecer las variaciones arteriales. Se revisaron retrospectivamente un total de 155 angiografías de ambos lados de la región cervical lateral por tomografía computarizada multidetector. Se evaluaron las variaciones anatómicas de las arterias supraescapular, cervical superficial y escapular dorsal. Las tres arterias se originaron individualmente en 67 casos $(23,8 \%)$. Surgieron por formación de un tronco en 214 casos $(76,2 \%)$. El tipo más común de formación del tronco fue el tronco cervicodorsal (107 casos; $38 \%$ ). Los otros troncos hallados fueron: el tronco cervicoescapular, el tronco cervicodorsoescapular, el tronco dorsoescapular, en 66 casos $(23,4 \%), 40$ casos $(14,3 \%)$ y 1 caso $(0,3 \%)$, respectivamente. Los orígenes de las arterias en la región cervical lateral pueden mostrar variaciones y las arterias pueden originarse desde la arteria subclavia o sus ramas, individualmente o por formaciones de tronco. Puede ser beneficioso conocer estas variaciones antes de los procedimientos quirúrgicos reconstructivos en cabeza y cuello. La angiografía por TC es un método no invasivo que permite evaluar la anatomía arterial y las variaciones en esta área.

PALABRAS CLAVE: Angiografía; Arteria; Tomografía computarizada; Colgajos de tejido libre; Región cervical lateral; Variaciones.

\section{REFERENCES}

Abrahams, M. S.; Panzer, O.; Atchabahian, A.; Horn, J. L. \& Brown, A. R. Case report: limitation of local anesthetic spread during ultrasound-guided interscalene block. Description of an anatomic variant with clinical correlation. Reg. Anesth. Pain Med., 33(4):357-9, 2008.

Adams, A. S.; Wright, M. J.; Johnston, S.; Tandon, R.; Gupta, N.; Ward, K.; Hanemann, C.; Palacios, E.; Friedlander,P. L. \& Chiu, E. S. The use of multislice CT angiography preoperative study for supraclavicular artery island flap harvesting. Ann. Plast. Surg., 69(3):312-5, 2012.

Angrigiani, C.; Grilli, D.; Karanas, Y. L.; Longaker, M. T. \& Sharma, S. The dorsal scapular island flap: an alternative for head, neck, and chest reconstruction. Plast. Reconstr. Surg., 111(1):67-78, 2003.

Atallah, S.; Guth, A.; Chabolle, F. \& Bach, C. A. Supraclavicular artery island flap in head and neck reconstruction. Eur. Ann. Otorhinolaryngol. Head Neck Dis., 132(5):291-4, 2015.

Bozlar, U.; Ogur, T.; Khaja, M. S.; All, J.; Norton, P. T. \& Hagspiel, K. D. CT angiography of the upper extremity arterial system: Part 2-Clinical applications beyond trauma patients. A. J. R. Am. J. Roentgenol., 201(4):753-63, 2003.

Calisir, C.; Simsek, S. \& Tepe, M. Variations in the popliteal artery branching in 342 patients studied with peripheral CT angiography using 64-MDCT. Jpn. J. Radiol., 33(1):13-20, 2015.

Chaijaroonkhanarak, W.; Kunatippapong, N.; Ratanasuwan, S.; Amarttayakong, P.; Umka, J.; Prachaney, P.; Namking, M. \& Pannangrong, W. Origin of the dorsal scapular artery and its relation to the brachial plexus in Thais. Anat. Sci. Int., 89(2):65-70, 2014

De Beule, T.; Van Deun, W.; Vranckx, J.; de Dobbelaere, B.; Maleux, G. \& Heye, S. Anatomical variations and pre-operative imaging technique concerning the anterolateral thigh flap: guiding the surgeon. Br.J.Radiol., 89(1063):20150920, 2016.
Gao, Y.; Yuan, Y.; Li, H.; Gu, B.; Xie, F.; Herrler, T.; Li, Q. \& Zan, T. Preoperative imaging for thoracic branch of supraclavicular artery flap: a comparative study of contrast-enhanced ultrasound with three-dimensional reconstruction and color duplex ultrasound. Ann. Plast. Surg., 77(2):201-5, 2016.

Haas, F.; Weiglein, A.; Schwarzl, F. \& Scharnagl, E. The lower trapezius musculocutaneous flap from pedicled to free flap: anatomical basis and clinical applications based on the dorsal scapular artery. Plast. Reconstr. Surg., 113(6):1580-90, 2004.

Ikka, L.; Mihalea, C.; Achour, N. B.; Khalek, H. A. \& Vacher, C. The origin of the dorsal scapular artery: anatomic variations and surgical applications. Surg. Radiol. Anat., 38(9):1021-7, 2016.

Karaman, B.; Battal, B.; Bozkurt, Y.; Bozlar, U.; Demirkol, S.; Sahin, M. A. \& $\mathrm{Tas}_{\text {s }}$ ar, M. The anatomic evaluation of the internal mammary artery using multidetector CT angiography. Diagn. Interv. Radiol., 18(2):215-20, 2012.

Kim, S. Y.; Lee, K. T. \& Mun, G. H. Reliable harvest of a dorsal scapular artery perforator flap by augmenting its perfusion. Microsurgery, 36(2):152-6, 2016.

Lischka, M. F.; Krammer, E. B.; Rath, T.; Riedl, M. \& Ellböck, E. The human thyrocervical trunk: Configuration and variability reinvestigated.Anat. Embryol. (Berl.), 163(4):389-401, 1982.

Moore, K. L.; Dalley, A. F. \& Agur, A. M. R. Clinically orientated anatomy. $7^{\text {th }} \mathrm{ed}$. Philadelphia, Wolters Kluwer Health/Lippincott Williams \& Wilkins, 2014.

Murata, H.; Sakai, A.; Hadzic, A. \& Sumikawa, K. The presence of transverse cervical and dorsal scapular arteries at three ultrasound probe positions commonly used in supraclavicular brachial plexus blockade. Anesth. Analg., 115(2):4703,2012 .

Ono, S.; Chung, K. C.; Hayashi, H.; Ogawa, R.; Takami, Y. \& Hyakusoku, H. Application of multidetector-row computed tomography in propeller flap planning. Plast. Reconstr. Surg., 127(2):703-11, 2011.

Patel, K. M.; Chu, S. Y.; Huang, J. J.; Wu, C. W.; Lin, C. Y. \& Cheng, M. H. Preplanning vascularized lymph node transfer with duplex ultrasonography: an evaluation of 3 donor sites. Plast. Reconstr. Surg. Glob. Open, 2(8):e193, 2014.

Reiner, A. \& Kasser, R. Relative frequency of a subclavian vs. a transverse cervical origin for the dorsal scapular artery in humans.Anat.Rec., 244(2):265-8, 1996.

Rozen, W. M.; Ashton, M. W.; Stella, D. L.; Phillips, T. J. \& Taylor, G. I. Magnetic resonance angiography and computed tomographic angiography for free fibular flap transfer. J. Reconstr. Microsurg., 24(6):457-8, 2008.

Sato, T.; Akita, K. \& Karada, N.Anatomic Variations in Japanese.Tokyo, University of Tokyo Press, 2012.

Shareghi, S.; Gopal, A.; Gul, K.; Matchinson, J. C.; Wong, C. B.; Winberg, N.; Lensky, M.; Budoff , M. J. \& Shavelle, D. M. Diagnostic accuracy of 64 multidetector computed tomographic angiography in peripheral vascular disease. Catheter Cardiovasc. Interv., 75(1):23-31, 2010.

Smit, J. M.; Dimopoulou, A.; Liss, A. G.; Zeebregts, C. J.; Kildal, M.; Whitaker, I. S.; Magnusson,A. \& Acosta, R. Preoperative CT angiography reduces surgery time in perforator flap reconstruction. J. Plast. Reconstr. Aesthet. Surg., 62(9):1112-7, 2009

Tan, O.; Yuce, I.; Kantarci, M. \& Algan, S. Evaluation of lower-limb arteries with multidetector computed tomography angiography prior to free flap surgery: a radioanatomic study. J. Reconstr. Microsurg., 27(3):199-206, 2011.

Weiglein, A. H.; Moriggl, B.; Schalk, C.; Künzel, K. H. \& Müller, U. Arteries in the posterior cervical triangle in man. Clin. Anat., 18(8):553-7, 2005.

Corresponding author:

Erdogan Bulbul

Balikesir University

Cagis Campus

Appl. and Research Hospital

Radiology Department

Altieylul, Balikesir

TURKEY

E-mail: drerdoganbulbul@yahoo.com

Received: 21-01-2019

Accepted: 08-04-2019 